\title{
DIE DOOPGETUIE
}

\section{Inleiding :}

Op versoek van die Kommissie van die Hoogeerwatarde Algemenc Kerkvergadering, het 'n kommissie ondersoek ingestel na verskillende gebruike i.v.m. die doop, o.a. ook na die bestaan van die gebruik om sg. „,doopgetuies" se name op te gee vir opname in de doopregisters. ') Hierdie studiekommissie wys op die bestaan van slegs een soort „doop. getuie" nl. op die soort doopgetuie wie se funksie dit oorspronklik was om, indien die ouers van die kind te sterwe kom, in die plek van dic ouers die doopbelofte na te kom. Verder wys die kommissie daarop dat die funksie van sulke doopgetuies later eintlik verval het en dic hele gebruik van die opgawe van doopgetuies eintlik net ' $n$ formalite $t$ geword het. Aangesien die studiekommissie van oordeel is dat die hele gemeente getuie daarvan is dat die ouers die doopbelofte afgelê het, beve:l die studiekommissie aan dat die gebruik om ,doopgetuies" op tc gec, ont. moedig moet word.

Hierdie bevinding en aanbeveling laat verskillende vrac ontstaan:

(i) Is dit die enigste soort doopgetuie?.

(ii) Is die praktyk om doopgetuies op te gee, versoenbar met dic doop?

(iii) Wat was die werklike bedoeling met die instelling van doop. getuies?

(iv) Moet die gebruik sondermecr ontmoedig word of watter weg moet die Kerk volg?

\section{II, Die verskillende soorte doopgetuies :}

(a) Die „Apostoliese Tradisie" van Hippolytus maak op driërrlisi wyse melding van getuies in verband met die doop, $\mathrm{nl}$.

(i) Caput XVI, 1 en 2 vermeld dat lidmate wat reeds gedoop is, nuwe bekeerlinge vir die dooponderrig moet kom voorstel, d.w.s. eintlik vir hulle moet getuie staan sodat hulle in die katechumenaat opgeneem kan word. Die gelowige staan dus getuie vir daardie voornemende dopeling. So betuig die gelowige in eerste instansie dat die voornemende dopeling met die evangelie in aanraking gebring is. Tweedens betuig hy dat die voornemende dopeling deur die aanraking met die evangelie, 'n legitieme begeerte om deur die doop in die kerk ingelyf te word en in die kerk onder die genademiddele te lewe, ontwikkel het. Derdens betuig hierdie getuies dat die voornemende dopeling gereed en bereid is om medeverantwoordelikheid vir en in die Kerk te aanvaar.

1) Vgl. Agenda van die Alg. Kerkvergadering, Bylae H.H.1. 
Hierdie tipe doopgetuie is kennelik die produk van 'n lewende apostolaat. In hierdie doopgetuie het ons te doen met 'n ge!owige lidmat van die Kerk wat met die evangelie uitgegaan het na die ongelowiges en daarna met die mense wat deur Woord en Gees gewek en getrek is, teruggekom het na die gemeente. Hierdie getuic is 'n apostolîre figuur wat alleen kan bestaan waar die gemeente bewustelik apostolêr lewe.

Niemand sal probeer ontken dat die kerklike situasie in Suid-Afrika en in die wêreld vandag, veral as gevolg van die groeiende post-christelike heidendom, van so 'n aard is, dat daar vir hierdie tipe doopgetuie 'n ruim plek in die Kerk bestaan nie. Hierdie doopgetuie-praktyk wat tog nog sporadies hier en daar voorkom, kan beslis ne ontmoedig word nie, maar moet veral aangemoedig word.

(ii) Dieselfde Apostoliese Tradisies van Hippolytus ${ }^{2}$ ) vermeld verder ditt 'n gelowige, wanneer die bekeerlinge dic dooponderrig klaar deurloop het, voordat hulle gedoop word, vir hulle moet getuie staan en verklaar: ". . . dat hulle die weduwees eer bewys het, die siekes besock het en elke goeie werk verrig het".

Eintlik is die hele gemeente geroepe tot hierdie tipe van doopgetuieskap. D:e kategetiese arbeid van die Kerk het ook tot taak om die voornemende belydende lidmaat te vorm vir die diens van God in die wêreld en tot annvaarding van die medeverantwoordelikheid vir die opbou van die Kerk. Die getuienis van hierdie doopgetuies kom dus eintlik daarop neer dat die voornemende belydende lidmat deur die kategetiese onderrig só gevorm is, dat die Kerk hom in sy midde kan en wil ontvang as 'n medeverantwoordelike meelewende lidmaat van die Kerk d.w.s. as 'n medegetuie vir die evangelie.

Ook vir hierdie opvatting van die doopgetuie is datar ruim plek in die Kerk. Dit moet sekerlik weer in ere herstel word. Dit is op stuk van sake die gemeente wat op hicrdie wyse deur nuwe, mondige lede gesterk word. Die gemeente is getuie vir die evangelie en deur te getuig dat daar nuwe mondige lede tot die gemeente toegevoeg is, getu'g die gemeente tog cintlik van nuwe triomfe vir die evangelie.

(iii) In Caput XXI, 3 en 4 word ook nog 'n derde tipe van getuie genoem. Vry vertaal lees hierdie twee paragrawe as volg: „En hulle (d.i. die dopelinge) moet hulle klere uittrek”. „En hulle moet die kinders cerste doop. As die kinders vir hulleself kan antwoord, laat hulle antwoord. Maar as hulle nie kan nie, laat hulle antwoord of enigiemand van hulle familie".

Hiermee word 'n nuwe moontlikheid an die orde gestel wat vir die 2) Caput XX, 1 en 2. 
praktyk van die kinderdoop van groot betekenis is. Hierdie doopgetuie neem eintlik vir die dopeling die verantwoordelikheid wat deur die doop op die dopeling geplaas word, op hom, omdat die ouers om een of ander rede nie dié verantwoordelikheid kan aanvaar nie.

Hierdie praktyk kom soms in Suid.Afrika voor waar een of albei van die oucrs oorlede is of nog nie belydenis van geloof gedoen het nie.

Met hierdie praktyk het ons egter in die onmiddelike omgewing van die bestaande gebruik om doopgetuies se name in die doopregister op te neem, gekom.

\section{(b) Die Doopgetuie as peetouer:-}

Die kommissie van ondersoek waarna reeds verwys is ${ }^{3}$ ) bevind dat die hele gemeente getuie is dat die ouers die doopbelofte afgelê het. Daarom bevind die kommissie dat die praktyk om doopgetuies op te gee eintlik nie sin het nie en gerus ontmoedig kan word. Die skrywer hiervan het egter nog nocit die opvatting teengekom dat die doopgetuie, getuie is van die feit dat die ouers wel die doopbelofte afgelê het nie. Hy het wel menige kere die opvatting teengekom dat daardie doopgetuies eintlik die peetouers, van die kind is ${ }^{4}$ ).

Hierdie doopgetuie is in elk geval 'n spesifieke newe-verskynsel van die kinderdoop en kom waarskynlik voort uit die christelike barmhartig. heidspleging en besef van mede-verantwoordelikheid vir mekaar. Daarom sal dit goed wees om nadert in te gaan op die vraag of hierdie praktyk sondermeer ontmoedig moet word.

(c) Vooraf moet hier nog eers gewys word op nog 'n gebruik van die woord "getuie" in verband met die doop. Ambrosius van Milaan 5) gebruik die woord in 'n heel ander sin. Hy sê: „Daarom het julle gelees dat die drie getuies in die doop een is; water bloed en gees...." Juis omdat die Heilige Gees die doop implementeer ${ }^{6}$ ) is Hy die Een wat instaan vir die geldigheid van die doop en vir die feit dat God in die doop aan mense iets „betuig en verseël”. By die spreke oor die doopgetuic is dit dus goed en nuttig om rekening te hou met hierdie Goddelike Getuie by die doop en met did dinge wat $\mathrm{Hy}$ in en deur die doop aan die mense doen.

\section{Die Doopgetuie as newe-verskynsel van die kinderdoop.}

Die reeds genoemde kommissie het eintlik net verwys na die doopgetuie wat eintlik in die Kerk bekendstaan as die peetouers. Dit wil voorkom of dit goed sal wees, om, voordat die bevinding van die kommissie

3) Sien vootnoot 1).

4) In S.A. is baie mense wat by hulle peetouers grootgeword het - veral kinders wat gedurende die Anglo-Boereoorlog verwees is.

5) De Mysteriis IV. 20.

6) 1 Kor, $12: 13$. 
gehandhaaf of verwerp word, eers na te gaan of die doopgetuie sous bekend in die Kerk, te rym is met die kinderdoop aldan nie. Dit kan miskien die beste geskied deur kortliks die doopgetuie-praktyk te toets aan die gronde vir die kinderdoop. ').

\section{(a) Die Fides aliena.}

Hierdie grond bestaan eintlik uit twee hoofmomente wat onderling saamhang nl. die verbondsgedagte en dié van die eenheid van de Kerk. Hieronder word verstaan dat die verbond en daarom ook die Kerk, klein kindertjies insluit. Die verbond sluit al die gelowige geslagte in. "). Volgens hierdie beskouing word die doop dan aan die kindertjies van die gelowiges bedien as teken en seël op Gods beloftes en Gods handeling. Daarom vra die doop ,geloof in actie ... dat met ja-zeggen gepaard gaat" ").

Indien die doopgetuie verstaan word as peetouer van die gedoopte kind, dan laat hierdie fides aliena grond vir die kinderdoop 'n ruim en sinvolle bestaansmoontlikheid vir die doopgetuie as pectouer in die Kerk toe.

Die peetouer se funksie lê in die verlengstrek van dié vin die ouers. So 'n peetouer onderneem eintlik, om, wanneer die ouer te sterwe kom of om een of ander rede nie meer die geestelike en stoflike versorging van die kind kan behartig nie, ten volle vir daardie kind as ouer in te tree. Dit bring natuurlik mee dat so'n peetouer nie net medeverantwoordelikheid vir die uitvoering van die doopbelofte aanvaar nie, maar ook vir die stoflike versorging van die kind, wanneer dit nodig word. Hierdie doopgetuie se ja-sê by die doop bestaan dan eintlik daaruit dat hy met medewete van die Kerkraad en op versoek van die ouers, homself tenvolle verantwoordelik stel vir die versorging en opvoeding van die gedoopte. In hierdie sin is hy in medeverantwoordelike wie se verantwoordelikheid eise aan hom mag stel, maar nie noodwendigerwyse hoef te stel nie.

(b) Daar is ook nog die fides infantilis en fides imputate - gronde wat ook in reformatoriese kring aangevoer word en geld as gronde vir die kinderdoop. Dit verander egter niks aan die feit dat die doopgetuie beskou word as peetouer en nie as getuie dat die doopouers die doopbelofte afgelê het nie. ${ }^{10}$ ).

Ook by hierdie opvattings van die doop word die doopgetuie se verantwoordelikheid gesien en verstaan as 'n verantwoordelikheid wat effektief word wanneer die ouers om watter rede ookal, nie meer instaat is om die kind geestelik en stoflik te versorg nie.

(c) Opsommend kan ons dus sê dat aldrie die gronde wat op reformatoriese erf angevoer en gehuldig word as grond vir die kinderdoop

7) Die gronde word hier slegs genoem sonder enige kritiese kommentaar.

8) Handelinge $2: 38$ en 39 .

9) Herderlijk Schrijven, Generale Synode der Ned. Herv. Kerk, 1947.

10) In Roomse kringe waar die formeel regte bediening van die sakrament wel belangrik is mag die doopgetuie natuurlik die funksie hê om te betuig dat die selfwerksame sakrament wel reg bedien is. 
nie net moontlik maak dat 'n doopgetuie kan bestaan nie, maar dit selfs sinvol kan maak. Gesien vanuit die kerk se roeping tot barmhartigheid in aanvaarding van verantwoordelikheid vir mekaar.

\section{Ontwikkelings en Afwykings.}

(a) Inrigtings vir die versorging van verweesde en verwaarloosde kinders het onteenseglik 'n verswakking van die peetouerskap meegebring. Omdat kinders van Kerkweë en later van Staatsweë in sulke inrigtings opgeneem is, is die peetouer se verantwoordelikheid wat effektief moes word waar die ouer nie meer kan of wil sorg vir sy kinders nie, die peetouer ontneem en oorgedra op 'n Kerk- of Staatsbeheerde inrigting.

Hiermee hang nou saam die feit dat deur wetgewing "') die peetouerskap eintlik weggeval het en oorgedra is op 'n kinderhof wat deur hofbevel kinders wat sorgbehoewend geword het, iewers by 'n kinderhawe onderdak bring. In hierdie wetgewing word daar geen voorsiening gemaak waardeur die peetouer regsbevoegdheid besit om sy peetouerskap te kan uitoefen nie. Toe die Kinderwet onlangs gewysig is om die aan. neming van kinders te vergemaklik is daar wel gedeeltelik voorsiening gemaak vir die peetouer om sy verantwoordelikheid te kan uitoefen deur by ' $n$ kinderhof aansoek te doen om sy peetkinders aan te neem. Tog is daar nog 'n verskil tusserl die aanneming van kinders en die uitoefening van pectouerskap, want by aanneming moet die kind die familienaam van sy aangenome ouers aanneem en sy eie familienaam prysgee. By die uitoefening van die peetouerskap het soiets nooit gebeur nie.

(b) Daar het ook ander ernstige afwykings ontwikkel i.v.m. die doopgetuie-praktyk. Dit gebeur soms dat een ouer nie 'n belydende lidmaat van die Kerk is nie. In Suid-Afrika kan so 'n ouer nie self sy kind voor doop hou nie. Dan wil sulke mense iemand anders in hulle plek by die doop laat staan. Gewoonlik kom hulle dan met een of ander familielid of vriend om die kind voor doop te hou.

Daar is besware teen so'n optrede in te bring. Veral by die fides aliena-grond vir die kinderdoop is daar uitdruklik sprake van geloof. By nadere ondersoek blyk dit gewoonlik dat dit die een ouer is wat wel belydende lidmaat is, wat nie alleen die kind voor doop wil hou nie. Die motiewe agter so'n optrede is dan ook aityd van alles behalwe 'n geloofs. aard. Dit is gewoonlik 'n soort van skaamte of vrees vir die publieke opinie of wat anders ookal wat hierdie optrede inspireer. Die Kerk doop egter die kindertjies van die gelowiges en nie die kinders van dergelike beskaamdes of bevreesdes nie.

Die verdere vraag is natuurlik in dié geval of die persoon wat hereid is om in die plek van die nie-belydende ouer, die kind voor doop te hou 11) Soos b.v. die S.A. Kinderwet. 
enige begrip het van die verantwoordelikheid wat hy op homself met so'n daad neem. Meestal blyk dit dat hierdie mense geen of 'n baie geringe begrip van die doop en die betekenis van die doop het en selfs ook kerklos lewe. Daarom is hulle gewilligheid baie dikwels 'n uiters opper' vlakkige gewilligheid om 'n vriend of familielid ,uit te help". $\mathrm{Na}$ 'n deurtastende en ernstige doopgesprek verdwyn hierdie gewilligheid ook meestal.

'n Ander situasie doen hom soms ook voor. Dit gebeur soms dat albei ouers van ' $n$ kind nog nie belydenis van geloof gedoen het nie. Dan kom die grootouers of ander familielede dikwels met die versoek om die kind voor doop te hou. Sulke familie-lede se name word dan opgegee as doopgetuies. Tog laat hierdie situasie ook baie vrae ontstaan veral omdat mense wat nie direk verantwoordelik sal wees vir die geestelike of stoflike versorging en opvoeding van die kind nie, die doopbelofte moet aflê.

Die grootste probleem is egter daarin geleë dat hierd e soort afwy. kings feitlik sonder uitsondering voorkom onder mense wat eintlik ain die rand van die Kerk lewe.

Daarom verbaas dit geensins dat sommige mense van opinie s dit die doopgetuie-praktyk ontmoedig moet word nie. Maar dan b!y die vraag nog : Sou die ontmoediging of eventuele afskaffing van die doop. getuie-praktyk die vrae en probleme wat daardeur onder die aandag van die Kerk kom, oplos of tot niet maak? Waarskynlik sal die vrae nog bly bestaan en moontlik nog vermeerder. As die doopgetuie-praktyk heeltemal gestaak word, sal die vrae wat deur die afwykings wakkergeroep word, net nie meer onder die aandag van die Kerk kom nie, maar hulle sal nog bestaan en moontlik ook nog vermeerder. As die Kerk dan nie meer van die probleme weet nie, sal die Kerk miskien meer gerus wees, maar dit sal vir die Kerk beslis nie bevordelik of heilsaam wees.

\section{Enkele voorstelle :-}

Die praktyk dat die doopgetuies die peetouers is het al sinvol in SuidAfrika bestaan en kan nou nog sinvol bestaan. Die Kerk is nie geroepe om af te skaf nie, maar om te hervorm. Daar bestaan geen rede om die doop' getuie as peetouer summier in die ban te doen nie. Daar kan verskillende dinge gedoen word tot hervorming van die hele praktyk.

(a) Die verantwoordelikheid wat die doopgetuie as peetouer by die doop aanvaar, moet wettig gemaak word. Die feit is nl. dat die peetouer onder die huidige wetgewing geen regsbevoegdheid het om tydens die lewe of na die dood van die ouer in te tree en sy verantwoordelikheid 
effek te laat neem nie. Die prosedure is só, dat in gevalle van verwesing of verwaarlosing van kinders d.m.v. een of ander kindersorgvereniging ' $n$ kinderhofsaak geopen word en die kinders na een of ander kinderinrigting gekomiteer word, sonder dat die peetouer enige geleentheid gebied is om sy belofte gestand te doen. Hy kan wel 'n aansoek doen om die kind of kinders wettiglik aan te neem, maar dan word hy op ' $n$ waglys geplaas en is daar geen waarborg dat hy kind of kinders by! wie se doop hyl getuie gestaan het, sal kry nie. Bowendien is 'n aanneming waardeur die kinders op die naam van die aangenome ouers geregistreer word nie dié ekwivalent van die uitoefening van die peetouerskap nie.

As die kerk die christelike barmhartigheidspleging en die christelike medeverantwoordelikheid vir mekaar ernstig wil neem, dan lê dit op die weg van die Kerk om met die owerheid te onderhandel, om, terwyl daar tog wetgewing oor kindersorg gemaak word, ook voorsiening te maak vir hierdie peetouerfiguur wat in die Kerk en onder 'n gelowige volk werklik nie 'n vreemdeling behoort te wees nie. Op hierdie wyse sal daar tenminste gesorg word dat 'n lewende persoon en nie 'n dooie inrig. ting nie, vader en moeder sal staan vir verweesde en verwaarloosde kinders. Selfs die beste inrigting is nog maar die derde beste moontlikheid vir die versorging van kinders. Deur so'n wettiging van die peetouerskap sal die kindersorginrigtings in elk geval nie afgeskaf word nie. Miskien sal deur so'n stap hoogstens gesorg kan word, dat hulle nie altyd so óórvol is nie.

(b) Kerklik gesien sal hierdie poging tot singewing aan die peetouerskap meebring dat die doopgetuies reëlmatig ingetrek moet word in die sielsorglike gesprek waar die verantwoordelikheid van die peetouerskap duidelik ingeskerp sal moet word.

Vanselfsprekend sal ook die diakens sulke peetouers wanneer hulle, hulle peetouerskap moet uitoefen ook met meer as net woorde, moet bystaan. Langs hierdie weg kan die doopgetuie as peetouer sinvol ingeorden word in die Kerklike barmhartigheidspleging en terselfdertyd 'n gebruik wat uit godsdienstige oorwegings onder ons volk geleef het nie sondermeer oorboord gewerp word nie.

(c) Wat die afwykings wat hierbo genoem is, betref, kan die Kerk vanweë die feit dat daardie afwykings gewoonlik so op die randgebied van die Kerk lewe, vanselfsprekend sulke afwykings nie goedpraat of toelaat nie. Die Kerk moet dit, wanneer dit onder sy aandag kom, beskou as 'n geleentheid, 'n geopende deur, om met sy kategese en sielsorg, mense wat eintlik buite of net op die drumpel staan, te kan inbring. Dit kan nie deur blote ontmoediging van 'n afwykende praktyk nie, maar deur. 
wanneer hy met so'n praktyk gekonfronteer staan, sy verantwoordelikheid as Kerk te aanvaar en die Woord te bedein.

\section{Slotopmerking:-}

In die lig van die oorwegings hierbo angestip, wil dit voorkom asof dit wenslik sal wees om eers verder te besin oor die funksie van die doopgetuie voordat die aanbeveling van die studiekommissie uitgevoer word.

J. I. de WET. 